\title{
O corpo como representação da mulher: uma análise de artigos de revista sobre comportamento
}

\author{
Andréa Cassia EFÂNGELO (USP)
}

RESUMO: Partindo do princípio de que, em geral, a mulher é considerada um ser predominantemente emocional, a partir da análise de um artigo de revista feminina, pautada nos postulados da Teoria da Argumentação, esta comunicação objetiva demonstrar a presença marcante da racionalidade neste tipo de publicação, assim como sua eficácia argumentativa.

PALAVRAS-CHAVE: Argumentação; Ethos; Pathos; Incorporação; Persuasão.

\begin{abstract}
Starting from the principle that women are usually considered predominantly emotional beings and based on the analysis of a feminine magazine article as well as in the postulates of the Theory of Argument, this communication aims to demonstrate the remarkable presence of rationality in this type of publication and its argumentative effectiveness.
\end{abstract}

KEYWORDS: Argument; Ethos; Pathos; Incorporation; Persuasion. 
Atualmente, percebe-se uma influência direta dos meios de comunicação de massa sobre seus destinatários, cuja linguagem pode interferir no seu comportamento social e ampliar seu conhecimento de mundo.

Diante deste fato, percebe-se a importância de se estudar a argumentação no jornalismo impresso. Este tipo de veículo comunicativo requer um esforço retórico e argumentativo maior que o rádio, a televisão e a Internet, os quais, graças aos benefícios dos recursos áudio-visuais, podem envolver imediatamente o destinatário, além de tornar viável a transmissão simultânea ao momento dos fatos.

Este esforço também se justifica devido ao grande número de publicações e ao desenvolvimento da mídia impressa, o que tem tornado os leitores mais críticos. Assim, as técnicas argumentativas desempenham papel fundamental para a conquista dos leitores.

Para angariar a adesão do público-alvo, o ato de convencer não é suficiente, é preciso persuadir, pois convencer é apenas uma primeira etapa, ao passo que persuadir consiste em conduzir o ouvinte a agir em conformidade com a convicção que lhe foi transmitida (1997).

Assim, o raciocínio lógico e a apresentação de provas objetivas não são suficientes para o êxito da argumentação. Antes, torna-se necessário atingir a vontade, os sentimentos e as emoções do interlocutor, através de argumentos plausíveis ou verossímeis.

Com esta finalidade, o orador deverá ser digno de crédito, o que justifica uma atenção especial no processo de construção da imagem do orador, obtida pela Retórica mediante a aplicação dos conceitos de ethos e pathos propostos por Olivier Reboul

O ethos designa "o caráter psicológico dos diferentes públicos, aos quais o orador deve adaptar-se" (1998,48). Trata-se da imagem que o orador projeta de si mesmo, sem que o diga explicitamente, mas através do efeito que causa, e este efeito refere-se ao pathos, definido por Reboul como "o conjunto de emoções, paixões e sentimentos que o orador deve provocar no auditório com seu discurso" (op. cit.)

$\mathrm{Na}$ verdade, ethos e pathos se complementam, uma vez que a interação entre o orador e seu auditório se efetua por meio da representação que fazem um do outro.

Baseado no acima exposto, as revistas precisam se empenhar na construção de sua própria imagem, tanto física quanto psicológica, a qual, segundo Ruth Amossy, decorre de todo ato de tomar a palavra. Desta forma, o estilo, as competências lingüísticas e enciclopédicas, e as crenças implícitas do locutor são suficientes para construir uma representação de sua pessoa. $(2005,9)$

Devido à sua força persuasiva, o ethos tem sido considerado a principal prova argumentativa. Por este motivo, tem sido estudado por vários teóricos, não apenas da Retórica, mas também da Pragmática e da Análise do Discurso.

Na Análise do Discurso, destaca-se o conceito de incorporação desenvolvido por Dominique Maingueneau. Maingueneau efetua um desdobramento do ethos da retórica tradicional. Segundo ele, o texto possui uma voz ou tom que possibilita ao coenunciador construir uma representação do enunciador, a partir de índices de diversas ordens fornecidos pelo texto. Essa representação desempenha o papel de um fiador, que se encarrega da responsabilidade daquilo que é dito. Assim, o fiador é o responsável pelo tom da enunciação e não o autor. 
Esta figura do fiador é composta por um caráter, que designa o conjunto de traços psicológicos atribuídos ao enunciador pelo seu modo de dizer e por uma corporalidade, que consiste nas determinações físicas do enunciador, no modo que ele se veste e se movimenta no espaço social.

Maingueneau introduz a noção de incorporação, que designa a ação do ethos sobre o co-enunciador, no sentido de conduzi-lo a se identificar com a movimentação de um corpo investido de valores socialmente especificados. Ele conclui sua exposição ao demonstrar como a incorporação opera em três registros indissociáveis. Inicialmente, a enunciação leva o co-enunciador a conferir uma corporalidade ao enunciador, textualmente. Em seguida, essa corporalidade possibilita aos sujeitos do discurso "incorporarem" os esquemas que definem uma determinada maneira de se relacionar com o mundo, na sociedade. E por último, esses dois fenômenos permitem a "incorporação" imaginária do destinatário ao grupo dos adeptos daquele discurso. (MAINGUENEAU, 2002: 97 -100)

Devido ao enfoque mais abrangente que Maingueneau atribui ao ethos, este trabalho tenciona identificar traços de identidade subjacentes a artigos de revista, baseando-se, sobretudo, no conceito de incorporação sem, no entanto, ignorar as preciosas contribuições de Perelman a este respeito.

É importante ressaltar, devido à limitação do corpus, composto por excertos de artigos das revistas Boa Forma e Pense Leve, que as conclusões aqui apresentadas constituem resultados parciais referentes aos artigos analisados. Dentro destes limites, não seria possível, tampouco, traçar o perfil que as revistas, em sua globalidade, projetam e estimulam.

Além disso, como a eficácia de um argumento é sempre relativa ao auditório a que se destina, objetiva-se verificar as diferenças que podem ocorrer na escolha dos recursos retóricos quando se tem auditórios distintos.

A análise será realizada mediante a identificação de indícios textuais que evidenciem a atribuição de aspectos psicológicos e físicos do enunciador, assim como dos recursos argumentativos empregados para estabelecer o relacionamento entre o enunciador e o enunciatário. Em seguida, será empreendida a comparação entre os argumentos adotados pelas revistas.

\section{Análise dos artigos de revista}

Nos trechos escolhidos, as revistas expõem o seu parecer acerca da origem da compulsão, sendo que a revista Boa Forma trata especificamente da compulsão alimentar, ao passo que a revista Pense Leve discorre sobre o assunto em termos genéricos.

A partir do título deste item, a locutora estabelece um diálogo com a interlocutora, convidando-a a se auto-questionar.

Trata-se de uma técnica argumentativa denominada por Perelman como deliberação íntima, através da qual a pessoa conversa consigo mesma. Para o filósofo,

“... o homem dotado de razão, que procura formar-se uma convicção, tem de desprezar todos os procedimentos que visam 
conquistar os outros: ele não pode, crê-se, deixar de ser sincero consigo mesmo e é, mais do que ninguém, capaz de experimentar o valor de seus próprios argumentos" (1997:45)

No decorrer do discurso, percebe-se a recorrência deste recurso: "Será que é o marido que faz questão de uma esposa nos moldes da boneca Barbie? Ou todas as amigas descoladas são do tipo alta e magra e você não pode ser uma exceção?"

Assim, em vários momentos, a psicóloga dialoga com a interlocutora, além de incluir-se no discurso, mediante o uso da $1^{\mathrm{a}}$. pessoa:

"Tudo para desmontar as armadilhas emocionais que atrapalham a gente"

"E, assim, com a destruidora sensação de que não somos boas suficiente para o resto do mundo..."

Assim, através destes recursos, ela aproxima-se da leitora, estabelecendo um vínculo de amizade.

Além disso, a credibilidade de seus argumentos é reforçada por sua função de psicóloga, recurso denominado por Perelman como argumento de autoridade.

Os argumentos de autoridade consistem da citação de um orador que inspire confiança no auditório. Seu emprego está relacionado diretamente à competência e à experiência da autoridade invocada, que vai legitimar o real que deriva dela.

$\mathrm{Na}$ verdade, em sua atividade profissional, é comum que os psicólogos se apresentem como "amigos" de seus pacientes, almejando, desta forma, criar um ambiente de familiaridade para que o paciente fale de seus problemas.

Nesta "mescla" de papéis, a psicóloga age de forma compreensiva, sem radicalismos, valorizando a mulher como um todo: "Costumo dizer às minhas pacientes que o corpo é apenas uma parte delas, o que não anula todo o restante".

Esta variação de caráter amigo e ao mesmo tempo profissional retrata a vida em seu cotidiano, uma vez que, no dia-a-dia, as pessoas desempenham vários "papéis", dependendo do local e das circunstâncias. Conseqüentemente, sua forma de agir e de se expressar irá variar em cada situação.

A incorporalidade do enunciador pode ser percebida quando ela sugere "pequenos ajustes que podem melhorar o visual", ou seja, um corpo que obedece aos padrões normais aceitáveis, nem gordo nem magro demais.

As características de seu caráter possibilitam a incorporação da leitora ao grupo de mulheres que compartilham a mesma preocupação, de ter uma boa aparência, sem a exigência de um padrão de beleza extraordinário.

No discurso da revista Pense Leve, observa-se vários elementos relacionados à formalidade. Dentre eles o uso de termos impessoais, como o particípio e o emprego da $3^{\mathrm{a}}$. pessoa do singular.

Ainda, aparecem vários argumentos de autoridade, como a teoria médica, o termo médico serotonina, a instituição Unifesp, a estatística - "filhos de pais jogadores têm cinco a sete vezes mais chances de desenvolver a doença".

Embora motive o leitor, ao afirmar que todos os casos são tratáveis, e aconselhe-o: "O primeiro passo, porém, é que a pessoa tome consciência do seu descontrole e procure ajuda", percebe-se, pelos indícios textuais acima mencionados, um tom impessoal, distante. 
Assim, o emprego de recursos formais reflete o afastamento do enunciador, diferenciando-o do enunciador de Boa Forma.

Apesar do artigo de revista ser um discurso de natureza opinativa, o enunciador procura imprimir um tom de discurso científico ao empregar recursos característicos deste gênero. Ao mesmo tempo, em vários momentos, poderia-se dizer que o discurso inclui elementos próprios de texto informativo, ao explicar a compulsão e seus efeitos, por exemplo.

A partir destes dados, depreende-se um caráter sóbrio, sério. O próprio enfoque do artigo estabelece um tom mais científico, encarando-o como uma doença.

Os elementos de distanciamento também tendem a colaborar para a formação de uma imagem de mulher madura, formal e elegante, como um repórter ou um portavoz, provavelmente trajando um terninho, de cabelo arrumado e maquiagem sóbria.

$\mathrm{Na}$ medida em que estende o tema da compulsão a outras áreas do cotidiano, além da alimentação, a revista aborda temas de conhecimento geral, os quais poderiam, inclusive, atrair a atenção de um público mais amplo, não necessariamente o feminino. Pode-se dizer que ela incorpora um grupo maior de pessoas, as que sofrem do transtorno ou que simplesmente têm algum interesse pelo assunto.

\section{Considerações finais}

Após a análise dos artigos de Boa Forma e Pense Leve, pode-se constatar que, embora discorram sobre o mesmo tema, existem diferenças marcantes quanto ao foco atribuído por cada uma.

Ao mencionar diversos argumentos de autoridade, a revista Pense Leve adota um perfil mais sério, voltado à lógica e à ciência.

Enquanto isto, a revista Boa Forma apóia-se basicamente no depoimento de uma psicóloga, ainda não conhecida, que defende um método de sua própria autoria.

$\mathrm{Na}$ verdade, seu ponto forte encontra-se no relacionamento de amizade e de companheirismo em relação ao enunciatário, enquanto que a revista Pense Leve estabelece um relacionamento mais profissional, técnico.

Assim, ao contrário do que ocorre na revista Pense Leve, que se preocupa com a saúde, ao discorrer sobre a compulsão, o artigo de Boa Forma objetiva, dentre outros aspectos, a boa aparência e a auto-estima de suas leitoras.

\section{REFERÊNCIAS BIBLIOGRÁFICAS}

AMOSSY, Ruth. (Org.). Imagens de si no discurso: a construção do ethos. São Paulo, Ed. Contexto, 2005. Título original: Images de soi dans le discours.

MAINGUENEAU, Dominique. Análise de textos de comunicação. 4a . ed. São Paulo, Cortez, 2002.

\& CHARAUDEAU, Patrick. Dicionário de análise do discurso. São Paulo, Contexto, 2004.

MOSCA, Lineide do Lago Salvador. A conquista feminina do espaço discursivo, In:

Educação e Linguagem. São Paulo, UMESP, v.2, n.2, 1999, 11-21.

. Discurso Publicitário e Tradição Retórica, In: Lumen Revista 
de Estudos e Comunicações. São Paulo, FAI, v. 5, n. 11, 1999a, 1-20.

PERELMAN, Chaïm \& TYTECA; Lucie Olbrechts. Tratado da Argumentação. $5^{\mathrm{a}}$. ed. São Paulo, Martins Fontes, 1997.

REBOUL, Olivier. Introdução à Retórica. 2a . ed. São Paulo, Martins Fontes, 1998.

\section{Anexo}

\section{Eu quero emagrecer?}

Batizado de Dieta Mental, o método desenvolvido pela psicóloga aposta no poder do autoconhecimento aliado à sabedoria da ioga. Tudo para desmontar as armadilhas emocionais que atrapalham a gente. A primeira arapuca aparece antes mesmo de a dieta começar. Ninguém pára para analisar por que quer perder peso. Será que é o marido que faz questão de uma esposa nos moldes da boneca Barbie? Ou todas as amigas descoladas são do tipo alta e magra e você não pode ser uma exceção? "Na maioria das vezes, a decisão de emagrecer vem de fora. É imposta pela sociedade que associa valor pessoal com a aparência: só as mulheres esquálidas são merecedoras de alguma coisa”, diz a especialista. E, assim, com a destruidora sensação de que não somos boas suficiente para o resto do mundo, não existe força de vontade que dê conta de uma transformação. "Costumo dizer às minhas pacientes que o corpo é apenas uma parte delas, o que não anula todo o restante", adverte Denise. Pensando dessa forma, fica mais fácil se aceitar à sua moda e conseguir partir para pequenos ajustes que podem melhorar o visual.

Dieta do sim. Boa Forma, São Paulo, julho de 2005. Seção Comportamento, 105.

\section{Compulsão: mais que um simples desejo}

A origem dos comportamentos compulsivos ainda não está totalmente esclarecida, mas os cientistas já encontraram pistas. Uma das teorias mais aceitas pelos médicos é que a compulsão resulta da combinação de vários fatores. Entre eles:

- baixos níveis de serotonina (mensageiro químico do cérebro ligado à sensação de bem-estar e satisfação).

_ estímulo familiar. Ambiente doméstico e traços hereditários podem influenciar a compulsão. Um estudo feito pelo Ambulatório de Jogo Patológico da Universidade de São Paulo (Unifesp), mostrou que filhos de pais jogadores têm cinco a sete vezes mais chances de desenvolver a doença.

- fatores sociais. Quando a sociedade valoriza mais a quantidade do que a qualidade, o aparecimento do comportamento compulsivo é facilitado.

_ busca pela liberdade. A compulsão seria uma tentativa de se livrar por alguns momentos das regras impostas no trabalho ou até em casa.

O bom dessa história é que todos os casos são tratáveis, geralmente por meio de psicoterapia e até medicamentos. Terapias alternativas como acupuntura e florais são coadjuvantes no tratamento. O primeiro passo, porém, é que a pessoa tome consciência do seu descontrole e procure ajuda. 
Compulsão: mais que um simples desejo. Pense Leve, São Paulo, agosto de 2005. Seção Comportamento, 43-44.

\section{Como citar este artigo:}

EFÂNGELO, Andréa Cassia. O corpo como representação da mulher: uma análise de artigos de revista sobre comportamento. Estudos Semióticos, Número 3, São Paulo, 2007. Disponível em <www.fflch.usp.br/dl/semiotica/es>. Acesso em "dia/mês/ano". 